\title{
Eficiência de produtos naturais no controle de Colletotrichum gloeosporioides em pimenta na pós colheita
}

\author{
Edilene Carvalho Gomes ${ }^{1}$, Ilka Márcia Ribeiro de Souza Serra ${ }^{1}$
}

\author{
${ }^{1}$ Departamento de Fitotecnia e Fitossanidade, Universidade Estadual do Maranhão, UEMA, CEP 65041-970, São Luís, MA. \\ Autor para correspondência: Ilka Marcia R. de Souza Serra (ilka.tt@gmail.com) \\ Data de chegada: 24/02/2013. Aceito para publicação em: 01/10/2013.
}

\section{RESUMO}

Gomes, E.C.; Serra, I.M.R.S. Eficiência de produtos naturais no controle de Colletotrichum gloeosporioides em pimenta na pós colheita. Summa Phytopathologica, v.39, n.4, p.290-292, 2013.

O objetivo do trabalho foi avaliar o efeito de produtos naturais na expressão da resistência a Colletotrichum gloeosporioides agente etiológico da antracnose, em frutos pós-colheita de pimenta. Os produtos acadian $^{\circledR}$, biopirol $^{\circledast}$, neemseto ${ }^{\circledR}$, quitosana e rocksil ${ }^{\circledR}$ foram aplicados em duas épocas, 48 e 72 horas antes da inoculação do patógeno, em tratamentos independentes, utilizando-se duas dosagens para cada indutor. Verificou-se uma diminuição no desenvolvimento do patógeno em todos os tratamentos, diferindo estatisticamente da testemunha. Na primeira época de aplicação (48h) os tratamentos com biopirol ${ }^{\circledR}$ seguidos do acadian ${ }^{\otimes}$ nas maiores dosagens, apresentaram menores lesões de antracnose em relação aos demais tratamentos desta época. Na segunda época de aplicação (72h) o produto acadian ${ }^{\circledR}$ foi o único que apresentou efeito significativo entre os demais tratamentos. Os resultados obtidos demonstram potencial dos indutores naturais no controle da antracnose em frutos de pimenta na pós-colheita.

Palavras-chave adicionais: controle alternativo, indutores, patógeno

\section{ABSTRACT}

Gomes, E.C.; Serra, I.M.R.S. Efficiency of natural products in controlling Colletotrichum gloeosporioides in postharvest pepper fruits. Summa Phytopathologica, v.39, n.4, p.290-292, 2013.

The aim of this study was to evaluate the effect of different natural products on the expression of resistance to Colletotrichum gloeosporioides, the etiologic agent of anthracnose, in postharvest pepper fruits. The products acadian ${ }^{\circledast}$, biopirol $^{\oplus}$, neemseto ${ }^{\oplus}$, chitosan and rocksil ${ }^{\circledast}$ were applied at 48 and 72 hours before the pathogen inoculation, in independent treatments, using two doses for each inducer. There was a decrease in the pathogen development for all treatments, statistically differing from the control. At the first application time (48h), treatments with biopirol ${ }^{\circledast}$ followed by acadian $^{\circledast}$ at larger doses led to smaller anthracnose lesions in relation to the remaining treatments at that period. At the second application time $(72 \mathrm{~h})$, acadian ${ }^{\circledR}$ was the only product to show a significant effect, compared to the other treatments. The obtained results demonstrate the potential of natural inducers to control anthracnose in postharvest pepper fruits.

Additional keywords: alternative control, inducers, pathogen

O cultivo da pimenta (Capsicum spp.) no Brasil ocorre em todo o território nacional, com produção em torno de $40 \mathrm{mil}$ toneladas (3), representando importante segmento do mercado agrícola brasileiro. As pimentas mais comuns no mercado brasileiro são 'Malagueta', 'Bode', 'Cumari do Pará', 'Murupi', 'Dedo de Moça', 'Jalapeña' e 'De Cheiro', comercializadas in natura $(3,11)$. A antracnose, causada por Colletotrichum gloeosporioides é uma doença de elevada importância econômica, responsável por grandes perdas nesta espécie na pós-colheita. A infecção tem início pelo aparecimento de pequenas lesões circulares e deprimidas que rapidamente se expandem por todo o fruto.

A utilização de fungicidas ainda é a principal medida para minimizar as perdas causadas por C. gloeosporioides nos frutos de pimentas. No entanto, a preocupação mundial com relação à poluição ambiental, riscos à saúde promovidos pelos agrotóxicos, somando à resistência de patógenos a fungicidas, têm levado ao aumento de pesquisas envolvendo a utilização de agentes alternativos, potenciais indutores de resistência, para o controle de doenças na pós colheita (5). Vários agentes bióticos e abióticos com efeito de indutores de resistência são citados na literatura, com potencial para o controle de patógenos em pós colheita. O presente trabalho teve como objetivo avaliar o efeito dos produtos naturais $\left(\right.$ Acadian $^{\circledR}$, Biopirol $^{\circledR}$, Neemseto ${ }^{\circledR}$, Quitosana, Rocksil ${ }^{\circledR}$ ) no controle da antracnose, causada por C. gloeosporioides, em frutos de pimenta (Capsicum baccatum L.) na pós-colheita, em diferentes dosagens e épocas de aplicação.

Os isolados de C. gloeosporioides foram obtidos de frutos de pimenta coletados em plantios comerciais da zona rural do município de São Luís - MA. O inóculo foi produzido em placas de Petri contendo meio de cultura BDA, e incubadas em B.O.D, por oito dias a $25 \pm 2^{\circ} \mathrm{C}$. Para o tratamento foram utilizadas pimentas da cultivar Dedo de Moça (C. baccatum), provenientes 
da CEASA do município de São Luis - MA, em estádio de maturação comercial. Os produtos naturais foram aplicado $48 \mathrm{e}$ $72 \mathrm{~h}$, em tratamentos independentes, antes da inoculação do patógeno através da imersão dos frutos por três minutos, em soluções dos produtos, sendo utilizadas as concentrações de 50 e $100 \mathrm{~mL} / \mathrm{L}\left(\operatorname{acadian}^{\circledR}\right) ; 10$ e $20 \mathrm{~mL} / \mathrm{L}$ (biopirol $\left.^{\circledR}\right) ; 5$ e $10 \mathrm{~mL} / 1$ (neemseto $^{\circledR}$ ); 0,35 e $0,70 \mathrm{~g} / \mathrm{L}$ (quitosana) e 15 e $20 \mathrm{~g} / \mathrm{L}$ (rocksil $^{\circledR}$ ). A testemunha consistiu na imersão dos frutos em água. Utilizouse delineamento experimental inteiramente casualizado em esquema fatorial $5 \times 2 \times 2$ (cinco produtos naturais $\mathrm{x}$ duas dosagens $\mathrm{x}$ duas épocas de aplicação independentes) e oito repetições por tratamento sendo que a repetição constituiu-se de um fruto de pimenta em pós-colheita. Em cada fruto tratado foram realizados pequenos ferimentos onde se depositou disco contendo C. gloeosporioides crescido em BDA. Os frutos foram mantidos por 24 horas em câmara úmida, à temperatura ambiente de $26 \pm 2^{\circ}$. A avaliação foi efetuada pela mensuração do comprimento da lesão, com auxílio de um paquímetro digital, em cada ponto inoculado. Os dados do diâmetro das lesões nos frutos de pimentas foram submetidos ao teste de Tukey a 5\%, para a comparação das médias.

Os resultados obtidos revelaram que os produtos utilizados foram eficazes na redução dos diâmetros das lesões da antracnose causada pelo patógeno Colletotrichum gloeosporioides em frutos de pimenta, constatando-se os tamanhos significativamente menores em relação à testemunha (Figura 1). Estudos revelam que tratamentos de origem biótica e abiótica fazem com que o fruto reaja produzindo uma série de respostas suficientes para limitar a infecção do patógeno.

Comparando os tratamentos da segunda época de aplicação (72 horas antes da inoculação do patógeno) observaram-se diferenças significativas em relação à testemunha, porém não houve diferença entre os tratamentos. Em relação aos resultados obtidos nos tratamentos da primeira época de aplicação (48 horas) houve diferenças estatísticas entre os indutores. Dentre os dez tratamentos avaliados, os indutores biopirol ${ }^{\circledR}$ e acadian ${ }^{\circledR}$ nas concentrações de $20 \mathrm{~mL} / \mathrm{L}$ e $100 \mathrm{~mL} / \mathrm{L}$, respectivamente, propiciaram maior redução na patogenicidade do agente causal, destacando-se dos demais tratamentos desta época.

Analisando as épocas de aplicação, não houve diferenças significativas entre as mesmas, exceto entre as épocas de aplicação do produto acadian ${ }^{\circledR}$, menor dosagem $(50 \mathrm{~mL} / \mathrm{L})$, e biopirol $^{\circledast}$, maior dosagem $(20 \mathrm{~mL} / \mathrm{L})$, apresentando melhores resultados quando aplicados 72 e 48 horas, respectivamente (Tabela 1).

Resultados satisfatórios no controle de algumas doenças causadas por fungos foram obtidos em vários patossistemas por meio da aplicação de Acadian ${ }^{\circledR}$ em diferentes dosagens. Podese relacionar os exemplos de Phytophthora capsici - pimenteira (9) e Plasmopara vitícola - videira (7). Sugere-se que o controle de patógenos fúngicos pela adição de Acadian $^{\circledR}$ esteja relacionado com o aumento da atividade solúvel das peroxidases e a concentração da fitoalexina capsidiol (7), concluindo que a aplicação do extrato de $A$. nodosum age de forma indutiva na resistência à patógenos.

Os resultados positivos para tratamentos com Biopirol ${ }^{\circledR}$ foram semelhantes aos obtidos por alguns autores que testaram o produto como biopesticida. Azevedo et al. (1) para controle de Bemisia tabaci em melão; Morandi Filho et al. (9) verificaram que o ácido pirolenhoso ativaria substâncias do metabolismo secundário, induzindo a resistência das plantas ao ataque de Argyrotaenia sphaleropa, importante praga em frutíferas.

Além do tratamento com Biopirol ${ }^{\circledR}$ e Acadian ${ }^{\circledR}$ foi possível visualizar o retardo no tamanho das lesões nos demais tratamentos, que apresentaram médias inferiores a $2,40 \mathrm{~cm}$, referente à testemunha (Tabela 1). A quitosana controlou a antracnose quando aplicado 48 e 72 horas antes da inoculação do patógeno, resultados semelhantes foram obtidos por De Capdeville et al. (6) ao tratar frutos de maçãs 48 ou 96 horas antes da inoculação, obtendo efeito positivo de quitosana no controle do mofo azul (Penicillium expansum).

Vários outros trabalhos em pós-colheita apresentaram resultados positivos utilizando a quitosana. Chien et al. (4) e Bautista-Baños et al. (2) constataram eficiência da quitosana na redução da severidade de $C$. gloeosporioides em mamão induzindo a atividade da quitinase e $\beta-1,3$ glucanase. Assim como a quitosana, os produtos neemseto ${ }^{\circledR}$ e o silicatado rocksil ${ }^{\circledR}$ apresentaram redução das lesões de antracnose. A literatura registra o efeito positivo do silício ( $\mathrm{Si}$ ) no controle de doenças fúngicas, como o do míldio pulverulento do pepino, abóbora e melão (8). Estudos recentes têm sugerido que além do efeito mecânico sobre a penetração dos esporos do patógeno no hospedeiro, o Si está envolvido com o acúmulo de compostos antifúngicos e ativação de enzimas relacionadas com a defesa e fitoalexinas. De acordo com Paul \& Sharma (10), extratos do nim promoveram, em seus estudos, alterações e estimularam mecanismos naturais de defesa constatando-se o aumento de peroxidases, compostos fenólicos e fenilalanina amônia-liase.

Os resultados aqui obtidos demonstram que os produtos acadian ${ }^{\circledR}$ e biopirol ${ }^{\circledR}$ foram mais eficientes no controle do patógeno, porém todos os produtos naturais estudados apresentaram efeito sobre o tamanho da lesão e podem ser utilizados no manejo da antracnose em frutos de pimenta em pós-colheita, bem como na redução da utilização de fungicidas empregados no controle do patógeno.

Tabela 1. Efeito dos produtos naturais sobre o tamanho da lesão da antracnose causada por Colletotrichum gloeosporioides em frutos de pimentas (Capsicum baccatum) em pós-colheita.

\begin{tabular}{lccr}
\hline & & \multicolumn{2}{c}{ Épocas de aplicação } \\
\cline { 3 - 4 } Produtos naturais & Dosagens & $\mathbf{4 8 h *}$ & $\mathbf{7 2 h *}$ \\
\hline ACADIAN & $50 \mathrm{~mL} / \mathrm{L}$ & $1,50 \mathrm{bA}$ & $1,25 \mathrm{bB}$ \\
BIOPIROL & $100 \mathrm{~mL} / \mathrm{L}$ & $1,12 \mathrm{cdA}$ & $1,21 \mathrm{bA}$ \\
& $10 \mathrm{~mL} / \mathrm{L}$ & $1,37 \mathrm{bcdA}$ & $1,45 \mathrm{bA}$ \\
NEEMSETO & $20 \mathrm{~mL} / \mathrm{L}$ & $1,06 \mathrm{~dB}$ & $1,37 \mathrm{bA}$ \\
QUITOSANA & $5 \mathrm{~mL} / \mathrm{L}$ & $1,37 \mathrm{bcdA}$ & $1,42 \mathrm{bA}$ \\
& $10 \mathrm{~mL} / \mathrm{L}$ & $1,31 \mathrm{bcdA}$ & $1,36 \mathrm{bA}$ \\
ROCKSIL & $0,35 \mathrm{~g} / \mathrm{L}$ & $1,32 \mathrm{bcdA}$ & $1,51 \mathrm{bA}$ \\
& $0,70 \mathrm{~g} / \mathrm{L}$ & $1,45 \mathrm{bcA}$ & $1,33 \mathrm{bA}$ \\
Testemunha & $15 \mathrm{~g} / \mathrm{L}$ & $1,57 \mathrm{bA}$ & $1,57 \mathrm{bA}$ \\
& $20 \mathrm{~g} / \mathrm{L}$ & $1,46 \mathrm{bcA}$ & $1,51 \mathrm{bA}$ \\
& Água & $2,40 \mathrm{aA}$ & $2,20 \mathrm{aA}$ \\
& CV \% & 14,35 & 16,81 \\
\hline
\end{tabular}

Médias seguidas pela mesma letra minúscula nas colunas e maiúscula nas linhas não diferem estatisticamente entre si pelo teste de Tukey ao nível de 5\% de significância. *Aplicação dos produtos 48 e 72 horas antes da inoculação do patógeno. 


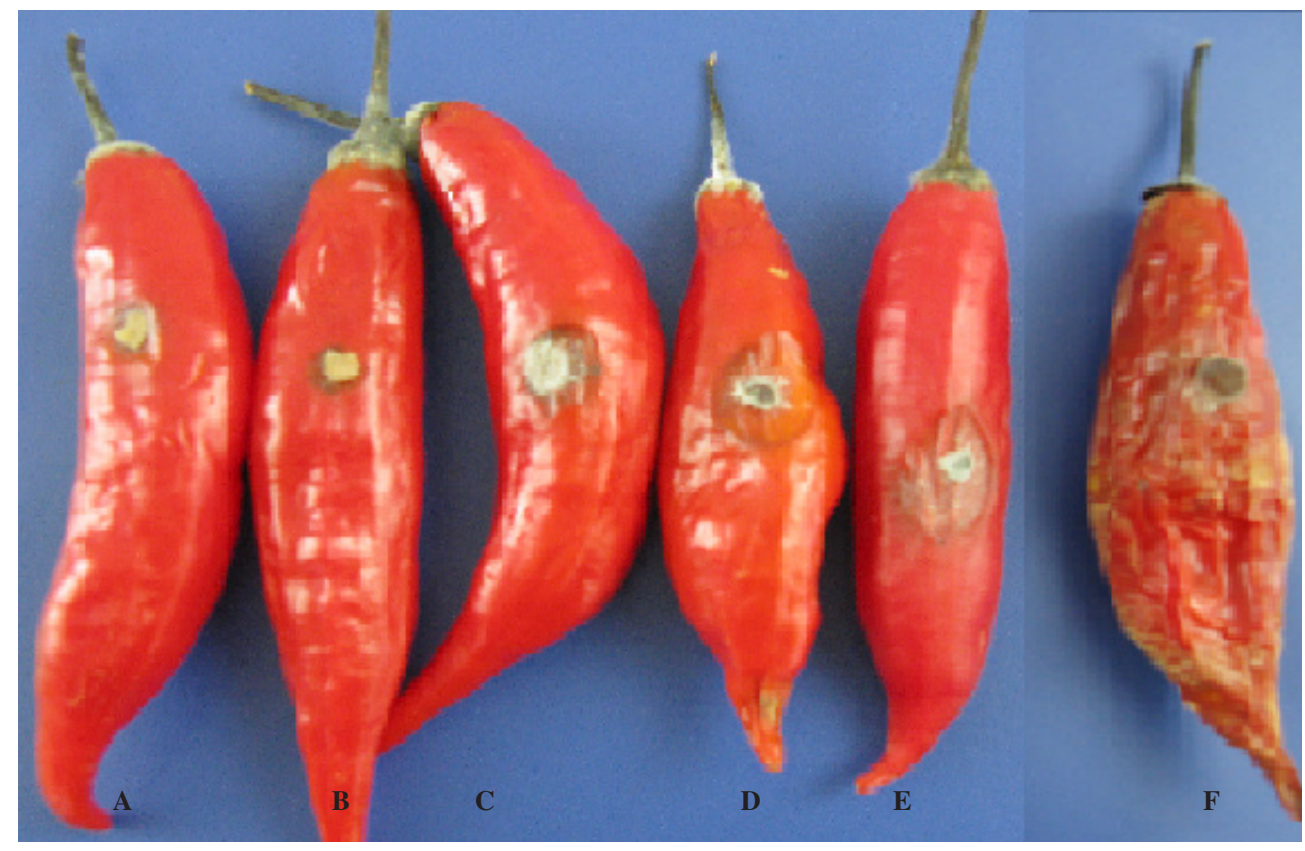

Figura 1. Efeito dos produtos naturais no controle de antracnose em frutos de pimenta. A- acadian ${ }^{\oplus}$; B- biopirol $^{\circledR}$; C- neemseto $^{\oplus}$; D- quitosana; Erocksil $^{\oplus} ; \mathbf{F}$ - Testemunha.

\section{REFERÊNCIAS BIBLIOGRÁFICAS}

1. Azevedo, F. R.; Guimarães, J. A.; Braga Sobrinho, R.; Lima, M. A. A. Eficiência de produtos naturais para o controle de Bemisia tabaci biótipo B (Hemiptera: Aleyrodidae) em meloeiro. Arquivos do Instituto Biológico, São Paulo, v. 72, n.1, p.73-79, 2005 .

2. Bautista-Baños, S.; López-Hernández, M.; Bosquez-Molina, E.; Wilson, C. L. Effects of chitosan and plant extracts on growth of Colletotrichum gloeosporioides, anthracnose levels and quality of papaya fruit. Crop Protection, Oxford, v. 22, n. 9, p. 1087 1092, 2003

3. Carvalho, S. I. C.; Bianchetti, L. B.; Ribeiro, C. S. C.; Lopes, C. A. Pimentas do Gênero Capsicum no Brasil. Brasília, DF: Embrapa Hortaliças, p.27, 2006. (Embrapa Hortaliças. Documentos, 94).

4. Chien, P. J.; Sheu, F.; Lin, H. R. Coating citrus (Murcott tangor) fruit with low molecular weight chitosan increases postharvest quality and shelf life. Food Chemistry, v. 100, p. 1160-1164, 2006.

5. Cia, P.; Pascholati, S.F.; Benato, E.A. Indução de resistência no manejo de doenças pós-colheita. In: Rodrigues, F.A.; Romeiro, R.S. (Org.). Indução de Resistência em Plantas a Patógenos. Anais da III Reunião Brasileira sobre Indução de Resistência em Plantas a Patógenos. 1 ed. Viçosa: UFV, v. 1, p. 245-268, 2007.
6. De Capdeville, G.; Wilson, C. L.; Beer, S. V.; Aist, J. R. Alternative disease control agents induce resistance to blue mold in harvest 'Red Delicious' apple fruit. Phytopathology, St. Paul, v. 92, n. 8, p. 900-908, 2002.

7. Lizzi, Y.; Coulomb, C.; Coulomb, PJ; Coulomb, PO; Polian, C. L'cara algue au Mildiou: Que avenir Phytoma, Paris, v.508, p. 29-30, 1998.

8. Miyake, Y.; Takahashi, E. Effects of silicon on the growth of cucumber plant in soil culture. Soil Science and Plant Nutrition, v. 29, p. 463-471, 1983.

9. Morandi Filho, W.J.; Botton, M.; Grützmacher, A.D.; Giolo, F.P.; Manzoni, C.G.; Action of natural products on the survival of Argyrotaenia sphaleropa (Meyrick) (Lepidoptera: Tortricidae) and selectivity of insecticides used in the organic production of vine on Trichogramma pretiosum Riley (Hymenoptera: Trichogrammatidae). Cie Rural v.36, n.4, p.1072-1078, 2006.

10. Paul, P. K.; Sharma, P. D. Azadirachta indica extrato da folha induz resistência em cevada contra a doença tarja folha. Patholology Planta Physiological and Molecular, Londres, v. 61, n. 1, p.3-13, 2002.

11.Vidigal, D.S.; Dias, D.C.F.S.; Pinho, E.V.R.V.; Dias, L.A.S. Alterações fisiológicas e enzimáticas durante a maturação de sementes de pimenta (Capsicum annuum 1.). Revista Brasileira de Sementes, Londrina - PR, v. 31, n. 2, p.129-136, 2009. 